\title{
TRIÂNGULO AMOROSO: UMA VARIAÇÃO DO AMOR NA CONTEMPORANEIDADE
}

\author{
Bruna Souza Rocha Oliveira* \\ Alessandra Leila Borges Gomes Fernandes**
}

RESUMO: Os vínculos amorosos passaram por uma intensa reestruturação ao longo dos séculos. Essas reestruturações fizeram com que, segundo Matos (2000), os vínculos amorosos contemporâneos ganhassem novas configurações, incluindo abertura nos relacionamentos, que pode significar desde a mobilidade de papéis para provedor e cuidador do lar, passando por casamentos em que os parceiros vivem em casas separadas até a concepção do poliamor - que quebra o paradigma do casal e insere outras formas (triângulo, quadrilha etc.) nas uniões afetivas. Tentando ler essas novas estruturas, este recorte analisa os triângulos amorosos presentes no conto "O corpo", de Clarice Lispector, "Triângulo em cravo e flauta doce" de Caio Fernando Abreu e no filme Os sonhadores, do diretor Bernardo Bertolucci. A partir da leitura e análise bibliográfica de referências como Engels (1984), Matos (2000) e Lins (2012), é possível estabelecer um panorama geral sobre os relacionamentos e o que conhecemos hoje como pacto de abertura nos enlaces amorosos. Busca-se, também, compreender o destino trágico que encerra as narrativas que abordam uniões diferentes, tendo em vista a noção de poliamor que desponta na paisagem contemporânea dos afetos como uma possibilidade. Pretende-se, assim, contribuir na disseminação das pesquisas científicas relacionadas ao estudo de relações amorosas, fomentando as discussões acerca das mudanças dos pactos afetivos.

PALAVRAS-CHAVE: Bernardo Bertolucci; Caio Fernando Abreu; Clarice Lispector; Representações amorosas; Triângulo.

\section{Apresentação}

Os seres humanos vêm se estruturando em pares, famílias e comunidades desde que nos sabemos gente. Ao longo do tempo, essas estruturas passaram a se configurar de diferentes formas, e o conceito de família vai assumindo diversos sentidos, de acordo com a somatória de convicções políticas, culturais e ideológicas de determinada sociedade e época. As uniões familiares já passaram de apenas junção de linhagens, para, a partir do século XVIII, incorporarem - gradativamente, com a ascensão da burguesia - a ideia de uniões

\footnotetext{
* Mestranda em Estudos Literários pela Universidade Estadual de Feira de Santana — (PROGEL/UEFS). Bolsista CAPES.

** Doutora em Estudos Literários pela Univsersidade Federal de Minas Gerais (UFMG). Professora da Universidade Estadual de Feira de Santana (Uefs).
} 
amorosas, na qual o vínculo estabelecido expunha, antes, o grau afetivo entre os pares, e não mais o financeiro, social ou familiar. Essa reformulação do casal também atinge a noção da monogamia e, posteriormente, ao laço conjugal moderno, que foi estabelecido juntamente com os ideais de individualismo e deu início à naturalidade com que se defende, de modo geral, a união por amor nas sociedades ocidentais.

Além dos ajustes nas noções de família, as configurações dos relacionamentos e das uniões afetivas também foram se transformando ao longo dos anos. Segundo Ferrari e Kaloustian (2002):

A família, da forma como vem se modificando e estruturando nos últimos tempos, impossibilita identificá-la como um modelo único ou ideal. Pelo contrário, ela se manifesta como um conjunto de trajetórias individuais que se expressam em arranjos diversificados e em espaços e organizações domiciliares peculiares. (FERRARI; KALOUSTIAN, 2002, p. 14)

Isso faz com que a premissa de par ou de casal usada para denominar a relação entre dois indivíduos de sexos diferentes não ocupe mais a posição de única união possível ou aceitável. Michelle Perrot discute essa assertiva, afirmando que "O bem-estar econômico da classe média e a influência religiosa em declínio alteram a percepção do objetivo do casamento, passando da satisfação de obrigações familiares e religiosas à satisfação das necessidades individuais" (PERROT apud Lins 2012, p. 135). Essa mudança de paradigma abre espaço para que também as artes tragam outras representações afetivo-sexuais, que diversificam a compreensão das experiências amorosas humanas.

As novas configurações amorosas não param de ocorrer e afetam as noções enraizadas de família. O núcleo familiar é o lugar onde mais podemos observar essas transformações, uma vez que seu dinamismo antecede e, muitas vezes supera, leis e regras sociais. Um exemplo comum foi a existência numerosa de famílias formadas pelo núcleo mãe-filho, em sociedades em que o divórcio ainda era proibido legalmente. Para Morgan, “A família é o elemento ativo; nunca permanece estacionada, mas passa de uma forma inferior a uma forma superior” (MORGAN apud ENGELS, 1984, p. 30). No que diz respeito à evolução dos vínculos familiares, esse autor nos esclarece que essas evoluções estão ligadas às demandas individuais que podem ser vistas no plano sociocultural dos grupos: 
A família é produto do sistema social e refletirá o estado de cultura desse sistema. Tendo a família monogâmica melhorado a partir dos começos da civilização e, de uma maneira muito notável, nos tempos modernos, é lícito pelo menos supor que seja capaz de continuar seu aperfeiçoamento até que chegue à igualdade entre os dois sexos. Se, num futuro remoto, a família monogâmica não mais atender às exigências sociais, é impossível predizer a natureza da família que a suceder. (MORGAN apud ENGELS, 1984, p. 91)

Segundo Camargo, no contexto contemporâneo, temos observado essas mudanças no que diz respeito à construção de novas famílias, sobretudo, as famílias homoafetivas. Para o autor, essas novas configurações "[...] provocaram tensões e rupturas com os padrões considerados hegemônicos em nossa sociedade” (2013, p. 84). Marlise Matos (2000) afirma que é possível percebermos a superação de valores que tradicionalmente orientavam o comportamento pessoal e social na modernidade. Com todas essas mudanças, antigos conceitos foram se reformulando, dando espaço para, segundo a autora, configurações amorosas distintas, como parcerias homo e heteroeróticas, acrescidas de outros desafios como pacto de abertura nos relacionamentos e/ou relacionamentos que envolvem questões poliamorosas.

Dentre os relacionamentos que envolvem questões de poliamor, estão os triângulos amorosos, que seriam, no imaginário social, a união de três pessoas em um mesmo relacionamento. Essa concepção de triângulo, no entanto, apresenta diversas divergências em suas representações dentro dos textos artístico-literários. Isso é possível de inferir quando interpretamos triângulos amorosos famosos que possuem uma estrutura diferente entre eles, como por exemplo o Rei Artur, seu cavaleiro Lancelote e Guinevere, sua esposa; Elizabeth, Mr. Darcy e Wickham, em Orgulho e preconceito (1813) de Jane Austen; Luísa, Jorge e Basílio em O primo Basílio (1878) de Eça de Queiroz; Capitu, Bentinho e Escobar em Dom Casmurro (1899) ou Camilo, Rita e Vilela em "A cartomante" (1884), ambos de Machado de Assis; Isabel, Álvaro e Cecília em O guarani (1857) de José de Alencar; Dona Flor, Vadinho e Teodoro em Dona Flor e seus dois maridos (1966), de Jorge Amado; entre tantos outros. Essas obras, mesmo possuindo um triângulo amoroso em sua trama, não trabalham com a reciprocidade entre as três pontas do triângulo, ou seja, não são relações poliamorosas, em 
que, conscientemente e de livre vontade, os três envolvidos se amam e se reconhecem como amantes.

Nosso interesse, neste recorte, é justamente o triângulo poliamoroso, em que todas as partes estão conscientemente envolvidas, ainda que não mantenham relações sexuais entre si. Para tanto, escolhemos "O corpo", de Clarice Lispector, e Os sonhadores, de Bernardo Bertolucci e "Triângulo em cravo e flauta doce", de Caio Fernando Abreu. Além de analisar a configuração desses enlaces, também nos interessam os aspectos trágicos, como a morte, que estão intimamente ligados a essas histórias.

O conto "O corpo" foi publicado em 1974, juntamente com outros treze contos no livro intitulado $A$ via crucis do corpo. Narrado em terceira pessoa, a história trata sobre a relação triangular, inicialmente bem sucedida, entre Xavier, Carmem e Beatriz. Xavier, homem de quarenta e sete anos. Carmem, mulher decidida e ativa, de trinta e nove anos. E Beatriz, mulher com características mais passivas, de cinquenta anos. Eles vivem em harmonia: as duas mulheres aceitam-se, sem conflitos, mantendo até mesmo certa relação de cumplicidade e amizade, sem que haja crise de ciúmes entre eles. Os três se relacionam abertamente e o conto mostra que são bem resolvidos sexualmente.

Na noite em que viu $O$ último tango em Paris foram os três para cama: Xavier, Carmem e Beatriz. Todo o mundo sabia que Xavier era bígamo: vivia com duas mulheres.

Cada noite era uma. Às vezes duas vezes por noite. A que sobrava ficava assistindo. Uma não tinha ciúme da outra. (LISPECTOR, 1974, p. 19)

Amam-se de forma igual e administram as próprias diferenças, fazendo com que a relação seja não apenas possível, mas equilibrada. Tão grande era harmonia entre o trio que eles chegam a ser comparados a uma famosa composição musical: "Às três horas da tarde foram os três para a igreja. Pareciam um bolero. O bolero de Ravel” (LISPECTOR, 1998, p. 21).

Assim era constituída sua família e viviam bem, apesar de não se enquadrarem nos padrões religiosos e constitucionais de organização familiar. Ao longo da narrativa, essa estabilidade entre os três é mantida até que a relação começou a tomar outro rumo. O 
triângulo bem estabelecido e que funcionava de forma harmônica começa a se sentir ameaçado porque uma quarta pessoa entra e desestabiliza a forma geométrica anteriormente escolhida: "Os três na verdade eram quatro, como os três mosqueteiros" (LISPECTOR, 1974, p. 20).

A estabilidade do triângulo ou a alteração da sua forma só é interrompida após o aparecimento de uma terceira mulher, uma prostituta, que leva a união ao desgaste, fazendo com que Beatriz e Carmem estreitem os laços entre si e se afastem mais de Xavier. Xavier tentou incorporar um quarto elemento na relação triangular, o que fez com que a relação desmoronasse, desequilibrando a igualdade do triângulo e desfazendo a forma:

Um dia Xavier veio do trabalho com marcas de batom na camisa. Não pôde negar que estivera com a sua prostituta preferida. Carmem e Beatriz pegaram cada uma um pedaço de pau e correram pela casa toda atrás de Xavier. Este corria feito um desesperado, gritando: perdão! perdão! perdão! (LISPECTOR, 1974, p. 23-24)

Após a quebra do triângulo amoroso, um elemento trágico veio compor as novas cenas. As duas mulheres tiveram a ideia de se livrar de Xavier, e assim o fazem. Tramaram a vingança e se livraram de uma das hastes quebradiças do antigo triângulo: "Foram armadas. O quarto estava escuro. Elas faquejaram erradamente, apunhalando o cobertor. Era noite fria. Então conseguiram distinguir o corpo adormecido de Xavier. O rico sangue de Xavier escorria pela cama, pelo chão, um desperdício” (LISPECTOR, 1974, p. 24). O resultado é a ruína do triângulo e o retorno ao par. Carmem e Beatriz, após matarem Xavier, se unem e partem, juntas, em viagem para Montevidéu.

“Triângulo em cravo e flauta doce" integra Ovelhas Negras (1995), último livro de contos lançado por Caio Fernando Abreu, que está dividido em três partes, indicando caminhos interpretativos com palavras chinesas: a primeira parte, ch'ien - traz oito contos cujos aspectos de força e da criatividade são propulsoras e formadoras do sucesso, numa alusão ao processo criativo do escritor. A segunda parte, k'an, simboliza a mutabilidade da água, e a necessidade de ser forte, e é também formada por oito contos atravessados pela dor. A terceira e última parte, ken, trabalha a simbologia do elemento da montanha, reco- 
nhecida pela imobilidade e impossibilidade de alteração, esses últimos oito contos remontam à perspectiva de narrar com a iminência da própria morte, numa relação forte com a ideia tradicional das Mil e uma noites, em que se narra para ganhar tempo e não morrer.

"Triângulo em cravo e flauta doce" está inserido na segunda seção ou parte k’na de Ovelhas negras. Originalmente, o texto foi escrito em 1971 e fazia parte de $O$ ovo apunhalado (1975), o terceiro livro de contos de Caio Fernando Abreu, no entanto, foi censurado pela direção do Instituto Estadual do Livro do Rio Grande do Sul que, à época, foi o responsável pela primeira edição de $O$ ovo apunbalado. $\mathrm{O}$ autor, porém, continuou tentando driblar a censura e, em 1978, conseguiu publicar "Triângulo em cravo e flauta doce" na Revista Ficção, um dos veículos mais importantes da literatura brasileira na década de 1970.

Narrado em primeira pessoa, o conto trabalha a angústia e a dor de uma relação incestuosa, composta por três irmãos: dois homens e uma mulher. A trama se inicia com o irmão-narrador e a irmã. A cena nos põe dentro de um diálogo indireto, olhos nos olhos, entre o irmão-narrador e a irmã que, gradativamente, através do filtro do seu interlocutor, vai nos informando das condições do conflito que cerca os três amantes. À medida que a conversa se desenvolve, a mulher revela que está grávida e pensa em abortar. Toda a sua subjetividade é, no entanto, mediada pelo irmão-narrador, que traduz a situação conflituosa como se fosse um pesadelo ou alucinação. Ao não dar voz direta à mulher, o conto de Caio Fernando Abreu suspende a possibilidade de nós, leitores, devassarmos a intimidade de uma das partes do triângulo, ao contrário, opta por representar essa parte, a feminina, através de marcas de uma fragilidade e intensa emoção: "Foi então que seus olhos se apertaram um pouco e por um momento pareceram cheios de lágrimas. Achei que fosse ilusão minha e não falei nada, até que ela começou a roer as unhas e afundou a cabeça na mesa" (ABREU, 1995, p. 168).

Conforme a conversa se estende, fica claro que a gravidez da mulher é algo perturbador para os três e, essa notícia da chegada de um quarto elemento, um filho, aliada à fragilidade da irmã, ao vício por drogas injetáveis do outro irmão e às constantes fugas do irmão-narrador, formam o núcleo tenso da narrativa: o incesto é o que costura a estranheza 
do triângulo aos olhos do leitor, mas é, também, o que une os amantes num universo próprio e indissolúvel. Inicialmente não sabemos que são irmãos, mas a história vai nos dando fragmentos, lembranças, vivências e ligações entre os três: "a mania de subir nas árvores mais altas e ficar lá em cima até que alguém a obrigasse a descer para jantar ou tomar banho" (ABREU, 1995, p. 170). A imagem inicial, de uma mulher perturbada e grávida, adquire nuances mais trágicas quando são revelados o vício por drogas injetáveis do outro irmão, sua agressividade e rejeição à ideia de uma criança entre eles, as fugas do irmãonarrador que vai e vem dentro do triângulo, a certeza da irmã sobre o aborto, única saída enxergada pela personagem para evitar uma tragédia maior. $\mathrm{O}$ irmão-narrador, contudo, tenta demovê-la:

Tentei acalmá-la dizendo que não era tão terrível assim, e fui repetindo como se fosse coisa decorada que: nas-pequenas-aldeias-gregas-isso-era-comum-e-que-em-alguns-países-da-Europa-e-mesmono-interior-do-Brasil-era-prática-normal-não-era-assim-tão-assustador. Sentindo-me vagamente ridículo, e também um tanto cruel, repeti que: vivíamos-um-tempo-de-confusão-e-que-todas-as-normasvigentes-estavam-caindo-que-aos-poucos-também-todas-as-pessoas-aceitariam-todas-as-coisas-e-que-talvez-nós-fôssemos-algunsdos-precursores-dessa-aceitação. Falei dessas coisas até cansar, enumerei nomes, contei lendas, lembrei mitos, mas não consegui evitar seu olhar de fera provocando tremores e abismos no fundo de minha voz. . (ABREU, 1995, pp. 170-71, grifos no original)

No fim da narrativa há a chegada do outro irmão, aquele de cuja agressividade a mulher falava. abre-se o quadro total da trama, e fica aparente o envolvimento amoroso entre os três irmãos:

Pensei absurdamente numa tia antiga fazendo doce de abóbora com cal num tacho preto, nós três em volta, e num esforço enorme consegui fechar os olhos. E enquanto a boca dele se aproximava da minha, muito aberta, vi nossa irmã atravessar o corredor de luzes apagadas, os olhos baixos, os dedos da mão esquerda pousados de leve sobre o ventre onde cresce meu filho. (ABREU, 1995, p. 172)

A presença do triângulo amoroso, composto por dois homens e uma mulher, é atropelado pela tragicidade de um fruto do incesto, um filho que é visto de forma conflituosa pelos próprios personagens, ainda que o narrador tende superficialmente minimizar 
esse impacto, na passagem acima citada, quando fala para a irmã que na Grécia ou em outros países o incesto não seria tão absurdo assim. Segundo Porto (2013):

\begin{abstract}
"Triângulo em cravo e flauta doce" relata a dor e a inquietação moral de três irmãos envolvidos numa relação incestuosa que se torna conhecida apenas no final da história, quando o narrador declara ser o pai da criança que sua irmã espera. Tendo plena consciência da sociedade e dos valores que esta prega, os personagens dessa narrativa manifestam em sua interioridade os reflexos de uma vida privada cujos comportamentos são socialmente condenados. O saldo de vida é o mal-estar, a dor e o sofrimento triplo de três sujeitos... (PORTO, 2013, p. 249)
\end{abstract}

O trágico se instaura muito mais a partir do embate com a chegada de um filho, um quarto sujeito, do que em razão de uma rejeição ou conflito psicológico dos três com o incesto. Nalguns momentos do texto, percebemos que se não houvesse a presença de uma ordem objetiva social, internalizada pelos personagens, condenando a vivência desse enlace afetivo e sexual, a autorrejeição ou angústia poderiam sequer existir e, talvez, a história tivesse um final menos trágico.

No filme Os sonhadores (2003), de Bernardo Bertolucci, também há dois irmãos: os gêmeos, Isabelle (Eva Green) e Theo (Louis Garrel), que vivem imersos numa realidade própria, construída minuciosamente a dois. Fato que comprova isso é a presença, durante toda a trama, de jogos, diálogos e intertextos criados pelos irmãos, que alimentam sua ligação. Theo e Isabelle são jovens franceses que conhecem outro jovem, Matthew (Michael Pitt), norte-americano, no contexto das manifestações políticas de 1968, em Paris. Quando os pais viajam, os irmãos convencem Matthew a morar com eles. Assim, começa a existir um estranho triângulo amoroso, que envolve autoconhecimento e os limites da sexualidade. Um triângulo que não parece ter os três vértices ligados entre si de forma harmoniosa, pois, apesar da cumplicidade que tentam cultivar, desde o início do filme percebemos que a relação dos gêmeos é marcada por disputas e conflitos, ainda que exponha, também, uma inocência, revelada pela inclinação às utopias socioculturais e políticas da época.

Imersos numa fantasia sobre liberdade, vida social, arte, cultura, sexo e amor, os irmãos atraem Matthew para compor o trio, apostando na quebra de paradigmas e num 
estilo de vida transgressor, que esse novo companheiro não só experimentaria como passaria a defender, qual diretor intervindo sobre os rumos de um personagem. Ambos os irmãos disputam quem seria mais "mentor" de Matthew, quem melhor o influenciaria a se tornar um transgressor. Mas a presença de Matthew faz com que os jovens sejam descobertos pelos pais e a fantasia em que viviam é exposta. É justamente neste momento em que a tríade Isabelle-Theo-Matthew é abalada, que o componente trágico - Isabelle tenta o suicídio - se incorpora à relação, assim como no triangulo construído em "O corpo", de Clarice Lispector, e Triângulo em cravo em flauta doce, de Caio Fernando Abreu. As obras, apesar de distintas, trazem aspectos chaves: a pluralidade de configurações amorosas, a fragilidade do triângulo amoroso frente a uma interferência externa e o fim trágico desencadeado por um quarto elemento, que faz ruir a relação estabelecida. Tomando essas relações triangulares, percebemos que as diferentes imagens dos triângulos amorosos são construídas de forma a quebrar a noção hegemônica da união amorosa representada pelo par ou dois, no entanto, não livra seus atores da tragicidade.

\section{O triângulo ou 3 em 1}

De acordo com Heródoto, o historiador grego, a geometria surgiu no Egito pela necessidade de se medir a terra por conta de inundações causadas pelo rio Nilo. Algumas figuras geométricas chamam atenção, mas o triângulo, em particular, tem seu prestígio, pois a resolução de muitos problemas da geometria elementar passa pela comparação de dois ou mais triângulos e a demonstração de certas propriedades fundamentais é feita considerando o uso dessas mesmas formas geométricas.

Os triângulos, embora aparentem serem sempre os mesmos, podem ser classificados, dependendo dos seus lados, em escaleno (três lados com medidas diferentes); isósceles (dois lados de mesmas medidas); ou equilátero (três lados de mesmas medidas). Pensando na história do triangulo, e do número três, é preciso que voltemos dois algarismos antes para que possamos entender a sua simbologia.

Comecemos pelo número um, número que dá nome à unidade dos seres e das coisas. Pascal dizia que todo o universo está contido na unidade. E temos manifestações de 
unidades supremas como Deus. O número Um, então, funciona como símbolo de integração, unidade maior, assim como é trazido nas religiões monoteístas como o centro do divino. Sendo o número um o algarismo que designa a unidade suprema das coisas, o número dois traz à tona a dualidade de tudo: dia e noite, bem e mal, sagrado e profano, tese e antítese, macho e fêmea, positivo e negativo etc. Essa dualidade, esse antagonismo que o número dois encerra, é resolvido com o número três, que traz a ideia da junção de elementos contrários para obtenção de um conceito ou síntese. Sendo assim, temos PaiFilho-Espírito, a santa trindade católica; negativo, positivo e neutro; tese-antítese-síntese; Id, ego e superego, de Freud, entre outros exemplos que afirmam um conceito a partir da interação entre três elementos. Sternberg $(1988 ; 1997)$, elaborador da teoria triangular do amor, também aponta que esse sentimento é composto por três elementos básicos: comprometimento/decisão, intimidade e paixão. A partir da delimitação dos três elementos fundamentais para a existência do amor, Sternberg (1988) argumenta que é possível fazer a combinação desses e obter diferentes tipos de amor. Para melhor compreensão, o autor correlaciona a sua teoria à figura geométrica do triângulo. Dessa forma, os três elementos formam os três vértices do triângulo. Sendo assim, o número três seria o número da síntese, da conciliação, do equilíbrio, mas que não anula a distinção ou diferença de seus componentes.

Extraindo a figura do triângulo da sua relação com a geometria e aplicando-a nas configurações amorosas, percebemos que, para que essa figura seja possível, é necessário que um terceiro elemento se interponha entre dois elementos principais, na relação amorosa, funcionando como a hipotenusa a unir dois catetos do triângulo. Se seguirmos como verdadeira toda essa teoria de que o número três é a articulação de elementos diferentes, que se equilibram na forma de um conceito, símbolo ou ideia, perceberemos que os triângulos amorosos trabalhados nos textos escolhidos expõem os impasses de uma coesão entre as partes. Significa dizer que mesmo buscando representar possibilidades amorosas incomuns, a linguagem artístico-literária não se esquiva de mostrar as armadilhas e contradições da condição humana. 
O conto "O corpo" envolve uma grande simbologia em torno do número três: ele é citado dezenove vezes, mostrando sua importância e sua carga simbólica na narrativa. Xavier, Camem e Beatriz é uma tríade fechada, abertos entre si, porque se amam e se relacionam com a mesma intensidade, mas fechados a outros componentes ou intervenções: "Cada noite era uma. Às vezes duas vezes por noite. A que sobrava ficava assistindo. Uma não tinha ciúme da outra" (LISPECTOR, 1974, p. 19). Sendo, portanto, um triângulo de lados iguais - equilátero, três lados com a mesma medida, três vértices que se relacionam da mesma maneira.

$\mathrm{O}$ amor das mulheres não era destinado apenas ao esposo, o amor era distribuído igualmente entre os três, de maneira que todas as hastes do triângulo se relacionavam. A forma triangular equilibrada só é rompida quando um quarto elemento é inserido. Nesse momento, a forma é desfeita e volta ao velho par: as duas se juntam para eliminar o homem e partem juntas numa viagem, qual Thelma e Louise ambicionavam fazer, no filme de 1991, de Ridley Scott.

No conto "Triângulo em cravo e flauta doce", a relação fraternal se erotizou, ao que parece, de maneira similar ao do conto "O corpo": três irmãos que mantêm relação afetivo-sexual entre si precisam lidar com uma gravidez não desejada, ou seja, novamente um quarto sujeito intervém e quebra o triângulo. As pistas dessa vivência amorosa são sutis e vão se desvelando página a página: o narrador ama a irmã e essa também o ama; a irmã ama ainda o outro irmão, que, ausente inicialmente, depois é inserido na história e entendemos, também, que esse último ama irmã e irmão ali presentes. "Abraçou-me com um carinho desesperado, acariciou-me os cabelos e as faces chamando-me lentamente de mano, meu mano" (ABREU, 1995, p. 171) e através dos carinhos destinados de um para o outro, visualizamos, também, a relação homoerótica dos dois rapazes. O final revelador do conto nos permite observar que os vértices do triângulo se unem igualmente, sendo assim um triângulo equilátero.

Em Os sonbadores, o triângulo entre Matthew, Isabelle e Theo se assemelha mais a um isósceles, com dois lado iguais (Isabelle e Theo) e um diferente (Matthew), que é o 
contrastante. A formação inicial é composta pelos irmãos Theo e Isabelle que, como gêmeos, buscam obstinadamente representarem duas hastes iguais: se parecem fisicamente, leem os mesmos livros, ouvem as mesmas músicas, cultuam os mesmos ícones, partilham das mesmas ideias e se desafiam mutuamente. Mas Isabelle não é o suplemento, para o irmão, da figura masculina faltante: ele precisa de um cúmplice em assuntos masculinos, assim como ele também não satisfaz à irmã em suas demandas por um parceiro-amante, que venha a ser seu primeiro homem. Matthew é essa a haste diferente, mas, para tanto, ele precisa ser iniciado no mundo peculiar dos gêmeos. Todavia, as diferenças e conflitos entre eles vão ficando cada vez mais perceptíveis e insustentáveis ao longo da trama. A forma geométrica construída pelos três só se equilibra temporariamente, diríamos mesmo que se alimenta de uma constante tensão entre os três, quando a amizade se mistura com a eroticidade e é costurada pela utopia, mas quando o sexo de concretiza entre Isabelle e Matthew, o triângulo sofre interferência dos pais dos gêmeos e passa por uma desordem.

$\mathrm{O}$ apartamento onde os jovens vivem é um paraíso que os preserva da realidade externa. $\mathrm{O}$ amor presente entre os irmãos franceses parece, inicialmente, não ultrapassar o amor fraternal, até a chegada de Matthew. Sem se darem conta de que o vínculo estabelecido por eles estava completo, os irmãos tentam inserir o jovem americano na relação, o que transforma a configuração amorosa preexistente entre os irmãos e o sonho que sempre os envolveu. O triângulo é praticamente desfeito por Matthew que, ao contrário do que se esperava, consegue separar, parcialmente, os irmãos da fantasia em que viviam inseridos durante toda a vida. A presença de Matthew na relação é um abandono do sonho, um chamado para a realidade.

\section{A forma de pontas trágicas}

Nas três obras analisadas, o triângulo é desfeito quando um intruso ou elemento externo tenta fazer da forma triangular outra forma geométrica. $\mathrm{O}$ triângulo que não suportou ser um quadrado se desfaz e volta à forma de par.

A descoberta da traição de Xavier e da possibilidade de uma nova pessoa na relação tripla faz com que as personagens femininas de "O corpo" sintam-se ameaçadas e traídas. 
Ódio, necessidade de vingança e violência passam a se manifestar dentro da relação. $O$ equilíbrio do triângulo se rompe e se transforma em tragédia. Eros, como sinônimo de erotismo, propulsor da vida, passa a Thanatos, sinônimo de ódio e agressividade, pulsão da morte. De forma parecida, a interferência de uma gravidez confunde os irmãos no conto de Caio Fernando, que mencionam o aborto (morte) como saída, e assim também ocorre com a intervenção dos pais dos gêmeos em Os sonhadores, influenciando Isabelle na tentativa de suicídio, desastrosa, porém não fatal.

O componente morte inserido nas narrativas é uma maneira trágica de impor novamente um equilíbrio, mesmo que represente a destruição ou ameaça de uma das hastes. Essa inserção não pode ser vista como rara, pois não é incomum encontrarmos nas representações amorosas literárias e artísticas esse entrelaçamento entre Eros e Thanatos: "vida e morte estariam, portanto, na origem da existência erótica" (BRANCO, 1985, p. 60). A morte ou a recorrência a ela é necessária para a restabelecer a ordem dos personagens, e deve ser lida não apenas na sua tragicidade, mas, sobretudo, no seu poder de transformação. Se é Eros que tende a construir laços afetivos, é Thanatos que opera no caos para que a desunião gere uma nova possibilidade de união. Segundo Lúcia Castelo Branco: “A força de Thanatos revela-se na posse amorosa que desemboca [...] nas manifestações violentas dos chamados crimes "por amor", ou do suicídio. Os amantes, quando se deparam com a impossibilidade da posse real do ser amado, terminam, muitas vezes, por preferir sua morte à sua perda" (1985, p. 63).

Entendemos que essa preferência pela morte consiste em matar a forma triângulo por completo, a fim de se libertar do sentimento trágico da dissolução. Embora essa consciência esteja mais clara no conto de Clarice Lispector, todos os triângulos analisados se inclinam para a busca de um ápice ou tragédia que, a partir do caos ou destruição, apontem uma nova possibilidade de configuração. É o momento, portanto, que Eros cede o lugar a Thanatos: "Foram armadas. O quarto estava escuro. Elas fraquejaram erradamente, apunhalando o cobertor. Era noite fria. Então conseguiram distinguir o corpo adormecido de Xavier. O rico sangue de Xavier escorria pela cama, pelo chão, um desperdício” (LISPECTOR, 1974, p. 24). 
Tanto nos contos "O corpo" e "Triângulo em cravo e flauta doce", quanto no filme Os sonhadores, o triângulo não permite se transformar num quadrado, antes, os envolvidos preferem vivenciar o trágico, seja na forma de homicídio, praticada pelas personagens clariceanas, seja na tentativa de suicídio de Isabelle, ou na menção ao aborto dos personagens de Caio Fernando Abreu. Enquanto no conto "O corpo", as duas mulheres se irmanam, cúmplices, e saem numa longa viagem, os personagens-irmãos de "Triângulo em cravo e flauta doce" mergulham na vertigem dos desejos, e os gêmeos de Bertolucci correm apressados para a rua, abandonando o jovem amante, atiram-se à frente do batalhão policial que pretendia deter a rebelião nas ruas de Paris. Esses dois triângulos, ao contrário do de Clarice Lispector, não efetivam a morte, mas a inserem na trama, enquanto mortes simbólicas, isto é, impedimentos ou situações de perda de referencial passadas pelas personagens ao longo da narrativa (JESUS, 2010).

Segundo Jesus (2010, p. 12) essa morte se coloca "como ideia que se configura na perda do referencial identitário e no aprisionamento do ser num tempo traumático e doloroso", assim como fica evidente nas descrições dos personagens durante o conto de Caio Fernando Abreu em que o triângulo é moralmente inaceitável, pois foge do padrão sociais predefinidos e das relações interfamiliares: a irmã transtornada, o irmão abusando de entorpecentes e da violência para tentar superar a situação tensa, e o narrador-personagem que sucumbe à vertigem do desejo e das lembranças. Os triângulos amorosos, quer num, quer noutro, dão lugar ao dois polarizador, que já nasce costurado pela violência e pelo desejo de desafiar os tênues limites entre vida e morte.

Esses caminhos diversos que os vínculos amorosos passaram, tanto no filme quanto nos contos, podem ser lidos como fruto de uma dificuldade cultural de aceitação do três ou da tríade, como possibilidade real de relacionamento afetivo duradouro. Eros transforma-se em Thanatos nas representações artístico-literárias, retornando ao antagonismo, à dualidade, ao par. Ao ver o triângulo se transformar em um quadrado, os amantes preferem reconfigurá-lo em dois, ainda que essa escolha aponte para a tragicidade ou perda dos vínculos amorosos. 


\section{LOVE TRIANGLE: \\ A VARIATION OF LOVE IN CONTEMPORANEITY}

ABSTRACT: Romantic relationships have undergone intense restructuring over the centuries. These restructurings made, according to Matos (2000), contemporary love bonds gain new configurations, including openness in relationships, which can mean from the mobility of roles for the provider and caregiver of the home, through marriages in which the partners live in homes separated until the conception of polyamory - which breaks the paradigm of the couple and inserts other shapes (triangle, quadrilha etc.) in the affective unions. Trying to read these new structures, this section analyzes the love triangles present in the short story "O corpo", by Clarice Lispector, "Triangulo em cravo $e$ flauta doce" by Caio Fernando Abreu, and in the film The dreamers, by director Bernardo Bertolucci. From the reading and bibliographic analysis of references such as Engels (1984), Matos (2000) and Lins (2012), it is possible to establish an overview of relationships and what we know today as an opening pact in loving relationships. It also seeks to understand the tragic fate that encloses the narratives that approach different unions, in view of the notion of polyamory that emerges in the contemporary landscape of affects as a possibility. It is intended, therefore, to contribute to the dissemination of scientific research related to the study of romantic relationships, fostering discussions about changes in affective pacts.

KEYWORDS: Bernardo Bertolucci; Caio Fernando Abreu; Clarice Lispector; Loving representations; Triangle.

\section{REFERÊNCIAS}

ABREU, Caio Fernando. O ovo apunhalado. São Paulo: Siciliano, 1975.

. Ovelhas negras. Porto Alegre: Sulinas, 1995.

BAUMAN, Zygmunt. Amor líquido: sobre a fragilidade dos laços humanos. Rio de Janeiro: Jorge Zahar Editor, 2004.

BRANCO, Lucia Castello. Eros travestido: um estudo do erotismo no realismo burguês. Belo Horizonte: UFMG, 1985.

CAMARGO, Flávio Pereira. Novas configurações familiares na Literatura Brasileira infantil e juvenil: leitura de Meus dois pais, de Walcyr Carrasco, e de Olívia tem dois papais, de Márcia Leite. Via Atlântica, n. 24. São Paulo: USP. 2013, p. 83-100.

ENGELS, Friedrich. A origem da família, da propriedade privada e do Estado. Rio de Janeiro: Editora Civilização Brasileira S.A, 1984.

FERRARI, M.; KALOUSTIAN, S. M. A importância da família. In: KALOUSTIAN, S. M. (Org.). Família brasileira: a base de tudo. 5. ed. São Paulo: Cortez: Brasília, DF: UNICEF, 2002. 
INSTITUTO BLAISE PASCAL: Tecnologia e Educação. Blaise Pascal. Disponível em: http://www.institutopascal.org.br/visao/institucional/blaisepascal.php Acesso em: 06 de dez. 2019.

JESUS, André Luiz Gomes de. As representações da morte e do morrer na obra de Caio Fernando Abreu. 2010. 185 f. Dissertação (mestrado) - Universidade Estadual Paulista, Instituto de Biociências, Letras e Ciências Exatas, 2010.

LINS, Regina Navarro. O livro do amor: do Iluminismo à atualidade. Rio de Janeiro: Best Seller, 2012.

LISPECTOR, Clarice. A via crucis do corpo. Rio de Janeiro: Rocco, 1974.

MATOS, Marlise. Reinvenções do vínculo amoroso: cultura e identidade de gênero na modernidade tardia. Belo Horizonte: UFMG, 2000.

OS SONHADORES. Direção: Bernardo Bertolucci. Produção: Gilbert Adair. Roteiro: Jeremy Thomas. Interpretes: Anna Karina, Eva Green, Greta Garbo, Louis Garrel, Michael Pitt, Robin Renucci e outros. [FRA/UK]: Fox Film, 2003. 130min.

PORTO, Luana Teixeira. Ovelhas negras: transgressão, violência e sofrimento. In: Revista Literatura em debate. v. 7. n. 12. Universidade Regional Integrada (URI), 2012. p. 247- 262.

RUFFATO, Luiz. Revistas literárias da década de 70. Jornal Rascunho, ed. 111. Disponível em: http:// rascunho.com.br/revistas-literarias-da-decada-de-1970-5/. Acesso em: 21 abr. 2020.

STERNBERG, R. J. Construct validation of a triangular love scale. European Journal of Social Psychology, 1997, p. 313-335.

. Triangulating love. In: R. J. Sternberg \& M. L. Barnes (Eds.). The psychology of Love. New York: Yale University, 1988, p. 119-138.

THELMA e Louise. Direção: Ridley Scott. Produção: Ridley Scott, Callie Khouri e Dean O’Brien. Roteiro: Callie Khouri. Interpretes: Susan Sarandon, Geena Davis, Harvey Keitel e outros. [USA]: Fox Films do Brasil, 1991. 2h30m.

Recebido em: 14/05/2020. Aprovado em: 30/05/2020. 